\title{
ZANG XXXIII TOT XXXVI, EN XXXVIII, XXXIX, L, LI VAN DEN NĀGARAKRTĀGAMA.
}

\author{
DOOR H. KERN.
}

\section{ZANG XXXIII.}

In dezen zang, in Narkuțaka-maat, worden bijzonderheden medegedeeld omtrent het verblijf van Hayam Wuruk in de kluizenarij te Sāgara ${ }^{1}$.

Nṛpati mahas ring āçrama wawang siněgěhsěgěhan| těkap ira sang mahārși mapalinggih açabda rěsěp| asung upabhoga salwir i bhinukti nire patapan | ṇ̣pati malěs yathākrama ring arttha lěwěs kasukan $\|1\|$

D. i. "De vorst ging rond in de kluizenarij en werd daarna op allerlei wijze onthaald door de gezeten Maharṣi's, die met innemende woorden alle genotmiddelen gaven die zij in de hermitage bezaten. De Vorst vergold die naar behooren met geld, ten zeerste vergenoegd».

Pangucapucap nirān gumuṇita rasa ning kawikun | paḍa mawarah ri sesi ni manah tan tinengöt | wěkasan acangkramālenngeng asing kalangwan pinaran | muhara ri tuṣța sang tapa tapi n-lumihat kawengan \| 2 \|

D. i. "In hun verschillende gesprekken beredeneerden zij de beteekenis van 't kluizenaarschap; zij deelden mede wat hun gemoed vervulde zonder achterhoudendheid. Ten slotte makte hij een wandeling, bekoord door alle mooie plekken die bezocht werden; hetgeen de vreugde wekte der kluizenaars en kluizenaressen, die met bewondering toekeken».

Ri huwus irānglěngöng majar i sang sutapan muliha | ri wijil irālaris hělahělā lumihat kawěkas | tapitapi sing rarānwam ahajöng paḍa kāryy angarang | Smara manurun mabañcana sireki hiḍ̌pnya n-akūng || 3 ||

1 Vervolg van blz. 202. 
D. i. "Nadat hij zich vermeid had, gaf hij aan de goede kluizenaars te kennen dat hij huiswaarts wilde keeren. Toen hij buitenkwam om zijn tocht voort te zetten, zagen de achterblijvenden opgetogen toe; de verschillende jonge en schoone kluizenaarsmeisjes bleven smachtend achter: verliefd, hielden zij hem voor den Minnegod die nederdaalde om hen te verleiden».

\section{ZANG XXXIV.}

Deze zang, in de maat Wasantatilakā, begint aldus:

Ryy antuk narendra kari sūksěka ${ }^{1}$ ng āçramoruk ! pringnyākuçāngěh abalut rî matālupā ken | anggöng tangis sěrěh ikāyam alas nịkāgrit| angluh ${ }^{2}$ tus ing tal angalěh syung ikānpasāmbat $\|1\|$

D. i. "Bij de terugreis des Vorsten bleef de kluizenarij bedroefd achter, in rouw. De bamboes treurden, ${ }^{3}$ gezwollen aan de oogen, met afgevallen bedekking; de betel weende ${ }^{4}$ al door; de boschhoenders schreeuwden; op tranen leek het uitvloeiende sap der wijnpalmen; droevig klonk er het geweeklaag der beo's.»

In deze schildering van verschijnselen aan planten en dieren zien wij een voorbeeld te meer van de neiging der Oudjavaansche dichters om verband te leggen tusschen 't wel of wee des menschen met de omringende natuur, die door uiterlijke teekenen als het ware deelneming toont aan 's menschen aandoeningen. Een klassiek voorbeeld van die dichtermanier geeft de uitvoerige natuurbeschrijving in Bhāratayuddha I, 10-16.

In de tweede strofe zet de dichter zijn verhaal aldus voort:

Asrět lari nrěpati n-aglis apan tumāmpa |

kweh ning yaçārěja kamārgga tělas kalalwan |

çìghrānḍatang sira ring Aryya sarātry anganti|

eñjing manguttara bhawișya ḍatang ri Gẹnḍing $\|$ | 2 ||

D. i. "De voortgang van den tocht des Konings werd (voor een tijd) gestuit, omdat hij dien (te) snel vond. Tal van prach-

1 De gedrukte tekst heeft sūkṣka. Elders vindt men gespeld sukṣka; vgl. KBWdb.

${ }^{2}$ De tekst heeft tegen de maat aluh.

3 Het woord angěh heb ik onvertaald gelaten, daar de beteekenis er van mij onbekend is.

4 Op welk eigenaardig verschijnsel aan de betel dit doelt, ontgaat mij. 
tige bouwwerken werden bezocht; na die voorbijgekomen te zijn, kwam hij weldra te Āryya, waar hij een nacht bleef. Den volgenden morgen trok hij noordwaarts en kwam daarna aan te Geṇụing».

De ligging van Āryya is mij onbekend. Daar Gẹnḍing oostelijk van Panaraga ligt, kan niet Āryya Blitar in Kẹdiri ${ }^{1}$ bedoeld zijn.

\section{Sang mantry amañcanagarì karuhun sang āryya| singhādhikāra ${ }^{2}$ nguniweh para Çaiwa-Boddha| kapwāhatur ttaḍah anindita sopacāra| mās wastra nāma pamalěs nụpati n-suke twas $\|3\|$}

D. i. "De Mantri's van de buitendistricten, voorafgegaan door den Āryya Singhādhikāra, alsmede de Çiwaietische en Buddhistische geestelijken, boden onberispelijke spijzen aan met verschuldigde plichtplegingen. De Vorst vergold die met goud en kleedingstoffen, blij van zin».

Arddhālawas ṇ̣pati tansah anganti māsa|

solah nireng sakuwukuww atika ng linolyan |

ryy angkat nirānhawan i Loh-gaway ing Sumaṇding |

Borang Bangor Barěmi tūt hěnu būny angulwan $\|4\|$

D. i. "Vrij lang vertoefde de Vorst, een maand aan één stuk. Zijne gedragingen in alle kampementen waren zóó dat men er meê ingenomen(?) was. Na opgebroken te zijn, nam hij den weg over Loh-gaway, Sumaṇḍing, Borang, Bangör, Barěmî, langs een -3 weg Westwaarts. »

Van geen der hier genoemde plaatsen heb ik met de mij ten dienste staande bronnen de ligging kunnen opsporen. Men zal ze moeten zoeken tusschen Geṇding en Pasaruhan.

\section{ZANG XXXV.}

De maat hiervan is een specie van $\bar{A} k r$ ti. De eerste strofe geeft het volgende te lezen:

1 Zie Verberk, Oudheden van Java, blz. 267.

- De gedrukte tekst heeft singäo tegen de maat. Mijne conjectuur is onzeker; mogelijk is bedoeld: singng $\bar{a}^{\circ}$, d. i. "de ambtenaren".

s Būni is onvertaald gelaten, daar de beteekenis van "geheim", die van 't Jav. buni wordt opgegeren, kwalijk past.

D1. 67. 
Tuhun i ḍatěng nire Pasuruhan manimpang angidul ri Kāpāñangan |

anuluy atūt ḍamārgga madulur tikang ratha ḍatěng ring Andohwawang |

muwah i Kẹdung-pěluk ${ }^{2}$ lawan i Hambal antya nikang pradeçenitung |

jhațiti ri Singhasāri-pura rājadharmma dinunung narendrāměgil || $1 \|$

D. i. "Maar te Pasuruhan gekomen, sloeg hij een zijweg in naar Kāpā̃̃angan; vervolgens den hoofdweg ${ }^{3}$ volgende met de karossen, kwam hij te Andoh-wawang, voorts te Kęḍung-pěluk en Hambal, 't einde van de opgenomen plaatsen. Onmiddellijk begaf de Vorst zich naar de residentie Singasāri-stad, waar hij zijn verblijf betrok.»

Tot afwisseling vertelt de dichter in de volgende verzen iets van zijn eigen verrichtingen.

Kunang ika sang Prapañca kari kulwan ing Pasuruhan pijer lālana| kuṭi mangaran rị̣ Darbaru ri bhūh pradeça nikanang pradeçe Hujung yata pinaran tinakwanakěn angça punpunan ikā ri sang sthāpaka likita tinonakěn rasika supraçāsti winacāmangun waspada \| 2 \|

D. ì. "Doch Prapañca bleef achter ten Zuiden van Pasuruhan, niets doende dan wandelen. Hij begaf zich naar een klooster, genaamd Darbaru, op den dorpsgrond van de desa Hujung, waar hij aan den opzichter inlichting vroeg aangaande de door 't klooster bezeten grondstukken. Bedoelde persoon gaf hem inzage van schrifturen, schoone charters, wier lezing licht verschaften.»

Ikang i lępit ${ }^{3}$ yathāswa salěbak wukirnya wiṣayāngça sang hyang kuți | satěngah i Markkaman sawah i Balunghura sawah muwah ring Hujung | rasa nikang praçāsti magawe hyun ing kawi madoha sangkeng pura ri taya nikang purākṛta ${ }^{*}$ těhěr daridra musira ng kuțiṇ Ḍarbaru || 3 ||

\footnotetext{
1 Da, de oorspronkelijke vorm van $\mathrm{ra}$, behouden na de $t$, evenals na neusklanken.

${ }^{2}$ De gedrukte tekst heeft Kḍ u pluk.

s Conjectuur voor hĕpit.

4 De lange a dient alleen om de lettergreep prosodisch lang te maken. Evengoed ware purakrĕta.
} 
D. i. "Het in de gevouwen bladen (vervatte), was (een opgave van) 't gebied behoorende aan 't heilige klooster, met de hooge en lage gronden ervan, afzonderlijk, gedeeltelijk te Markaman, de sawahs te Balunghura, voorts de sawahs te Hujung. De inhoud der charters wekte den lust op van den dichter om van de stad verwijderd te blijven; daar hij in de stad niets te maken had, gevoelde hij behoefte om het klooster van Darbaru op te zoeken.»

Karaṇa ning açru mangkat huwus nira $\mathrm{Mpu}$ masěgěh bhawîșyālaris ${ }^{1}$ | maluy i kasewakan d̦atěng i Singhasāri matutur manangkil marěk | ṇ̣pati huwus mamuspa ri dalěm sudharmma sakatușta ning twas ginöng |

hanan i Kẹ̣ung-biru ri kasurāngganān mwang i Burěng langönyenitung $\|4\|$

D. i. "Daar ik reden had om spoedig (weêr) te vertrekken, zette $\mathrm{ik}$, nadat de Hoogeerwaarde mij onthaald had, de reis voort, en keerde tot mijn dienstplicht terug. Te Singhasāri gekomen, maakte ik, indachtig (aan mijn plicht), mijne eerbiedige opwachting. De Vorst, na lof gebracht te hebben in den graftempel ${ }^{2}$, gaf zich over aan al de geneugten zijns harten, of te Kẹdung-biru in 't Hemelnimfenhof ${ }^{3}$; en te Burěng werden de bekoorlijkheden der plaats beschouwd (?).»

De genoegens welke de jeugdige heerscher smaakte, waren, naar men veronderstellen mag, meestal van erotischen aard.

\section{ZANG XXXVI.}

Deze Zang, in de maat Açwalalita, verhaalt van 't bezoek des Konings aan den graftempel te Kageněngan, waar, gelijk men weet, de stichter der dynastie van Tumapěl, Rājasa, na zijn dood in Çaka 1169 werd bijgezet en aan zijne nagedachtenis goddelijk eer bewezen. Het tijdstip waarop dat bezoek plaats had, wordt niet bijzonderlijk vermeld; maar wij mogen de gebeurtenis stellen kort na de terugkomst van den jeugdigen heerscher in de hoofdstad na zijne rondreis.

1 De gedrukte tekst heeft oy anglaris.

${ }^{2}$ Hiermede schijnt bedoeld te wezen dat de Koning in 't heiligdom eerbiedig dank brengt voor zijn behouden terugkomst.

3 Dit Hemelnimfenbof doet denken aan 't "Pare aux cerfs" van Lodewijk XV. 
Krama çubhakāla sah nira ri Singhasāri mangidul mare Kagěněngan | humaturakēn kabhaktin i Bhațāra dharmma sawatěkwatěk nira tumūt| dhana paribhoga bhojana dulur ni puspa nira sopacāra mahalęp | saha wasanāwawan watang apangruhun paḍa magarjjita ${ }^{1} \mathrm{ng}$ wwang umulat $\|1\|$

D. i. «Vervolgens op een gunstig tijdstip vertrok hij uit Singasāri Zuidwaarts naar Kagěněngan. Hij bracht met de talrijke scharen die hem volgden hulde aan den Bhațāra (vergoddelijkten heerscher) van den graftempel. Geld, voorwerpen ten gebruike, spijzen volgden zijn staatsiekoets ${ }^{2}$ met prachtige insigniën, met doeken uitgespreid op staken en voorloopers (?); alle toeschouwers juichten.»

Ri huwus irānpangarccana mijil ri heng pinupul ing balākrama marěk | para wiku Çaiwa-Sogata sang āryya $n \bar{a} l i g i h^{3}$ iniring nireki $\tan$ adoh awicaritan sẹ̣̆eng ni panaḍah narendra tuměkāni seșța ri hati| bala haji sing sasambhawa wineh suwastra magawe rěsęp ning umulat || 2 \|

D. i. "Nadat hij zijne vereering gebracht had, trad hij naar buiten, waar hij omstuwd werd door onderdanen die in volgorde hun opwachting maakten: Çiwaietische en Buddhistische geestelijken, die op korten afstand Ārya - vergezelden. Onnoodig te zeggen, dat ten tijde van 't maal de Vorst voldeed aan wat zijn hart begeerde. De koninklijke troepen, voor zoover tegenwoordig, werden begiftigd met mooie kleederen, hetgeen de toeschouwers aangenaam aandeed.»

Van den volgenden Zang, (XXXVII) waarin een beschrijving van 't heiligdom te Kagěněngan gegeven wordt, vindt men een vertaling in Dl. 65 , blz. 128 , dezer Bijdragen. Uit het laatste vers van dien Zang blijkt dat de dichter rust hield in Barěng, hetgeen hem aanleiding geeft een beschrijving te

1 Zoo leze men voor hagarjjita.

2 Puspa kan hier kwalijk iets anders wezen dan een wanvorm ontstaan uit een verkeerd gelezen Skr. puṣya-ratha, Pāli phussa-ratha. Trouwens ook in Skr. teksten is puṣpaka voor puṣyaka zeer gewoon.

$s$ Corrupt; één korte lettergreep te veel. 
geven van de omstreken dier plaats in 't begin van den volgenden Zang.

\section{ZANG XXXVIII.}

De maat hiervan is welbekend in de Indische prosodie onder den naam van Wamçapatrapatita.

Rāmya nikā(ng) Burěng talaga mumbul ahěning abiru| caṇdi çilā minekala ri madhya nika rinacana| sök yaça munggwi i pinggir ika len kusuma caracara | lot paran ing macangkrama lanāngjěněki ring umara \|1 ||

D. i. "Het liefelijke van Bureng is de heldere, blauwe vijver die (als uit den grond) opwelt; een Tjaṇḍi van natuursteen voorzien van een mekhala (gordel) is in 't midden er van gebouwd; talrijke gebouwen staan aan den zoom en allerhande bloemen. (De plaats) is zonder ophouden 't doel van wandelaars en vervult degenen die er heen gaan steeds met behagen.»

Tan wuwusěn langö nikā tuhun narapati caritan | tistis ing arkka mangkat ahawan tegatěgal aruhur! rāmya dukut nikātětěl ataṇḍes akiris ahijo | lwānya sasāgarānak angalun jurang ika dinělö || 2 \|

D. i. "Wij zullen niet (meer) over de bekoorlijkheden daar spreken, maar van den Vorst vertellen. Bij 't afnemen der hitte van de zon, vertrok hij, den weg nemende over de hooge těgalvelden, waar dicht, schoon, effen, groen gras prijkte, en waarvan de uitgestrektheid als een kleine zee bedriegelijk scheen te golven.»

Van de volgende verzen is reeds bij een andere gelegenheid een vertaling gegeven. De korte inhoud er van is deze, dat de Vorst na zijn uitstapje naar Singasāri terugkeerde, terwijl onze dichter van de gelegenheid gebruik maakte om een bezoek af te leggen bij een voornamen Buddhistischen monnik, den hoogbejaarden Sthāpaka van den graftempel. Deze eerwaardige, bijna honderdjarige grijsaard, die, - zooals wij uit Zang 49, 5 vernemen - Ratnāngça heette, had onder zijn berusting geslachtsregisters of kronieken. De dichter, begeerig om zijne geschiedkennis te vermeerderen, verzocht zijn gastheer dat deze hem een overzicht zou geven van de voorvaderlijke geschiedenis, 
te beginnen met de regeering van Rājasa (Ken Angrok) '. Het antwoord van den ouden heer leest men in den volgenden Zang.

\section{ZANG XXXIX.}

De verzen zijn in de dichtmaat Bhujangaprayāta. De eerste strofe luidt aldus :

Tuhun pāduka Mpuñkwi mungguh sirojar| uḍū diwya, takwan rakawy āngěne twas | mahotsāha singgih kawi wrěddhabuddhi| purih ning kaçāstrajñan ${ }^{2}$ angde stutìng rāt $\|1\|$

D. i. "Doch Zijne Eminentie de waardige Monseigneur zeide: "O, voortreffelijk! de vraag van $U$, groote dichter, treft het hart. Van grooten ijver, inderdaad, zijn de dichters van ontwikkelden geest. Het streven naar wetenschap bezorgt roem in de wereld.»

De oude man gaat met zijn vriendelijke toespraak aldus voort:

Nda sangtabya teki nghulun mājarosěn | maçucya wway ing saptatîrtthwe swacitta | namás te Girīndrāya sambah ri sang hyang | nda tan dadya kotpāta teki mpaçabda \| 2 \|

D. i. "Nu met Uw verlof zal ik aanstonds spreken. Moge het water der zeven heilige badplaatsen in 't eigen gemoed rein wezen! Hulde aan Girindra (Çiwa)! vereering aan de goden! En moge er geen (ongunstig) voorteeken plaats hebben terwijl ik het woord voer!»

De inhoud van deze strofe geeft aanleiding tot ettelijke opmerkingen. Ten eerste zij de aandacht gevestigd op den bijzonder beleefden toon dien zulk een voornaam personage als Ratnāngça - hij was van vorstelijke familie - tegenover zijn gast aanneemt, waarbij hij zich bedient van een nederig voornaamwoord dat men in onze taal zou kunnen weêrgeven met " $\mathrm{Uw}$ dienaar». Voorts is het kenmerkend dat hij zijn verhaal laat voorafgaan van een mańgala, een heilbrengend begin, zooals

1 Het is karakteristiek dat voor Prapañca de „oude" geschiedenis begint met Çaka 1104. Van wat er vóór dien tijd gebeurde, verlangt hij niet iets te vernemen. Het is alsof de geschiedkundige overleveringen van den vroegeren tijd waren uitgewischt of opzettelijk aan de vergetelheid werden prijsgegeven.

${ }^{2}$ Verbeterd uit istrajan van den gedrukten tekst. 
gebruikelijk is in den aanhef van geschriften. Wat met de "zeven heilige badplaatsen» in 't gemoed bedoeld is, weet ik niet te verklaren. De uitdrukking saptatìrtha wordt toevallig ook vermeld in KBW. d. b. onder sapta, maar zonder dat we daardoor iets wijzer worden. Misschien hebben wij te doen met een rhetorische figuur, waarvan de zin hierop neèrkomt: "moge mijn gemoed bij de mededeeling welke ik doen zal zóó rein wezen als het water der zeven heilige badplaatsen" - welke die zeven dan ook zijn. Merkwaardig, eindelijk, is het, dat de spreker, hoewel een Buddhist, hulde brengt aan Çiwa en de (overige) goden, vermoedelijk omdat de persoon met wien zijn verhaal begint, de stichter van de dynastie van Tumapěl, Koning Rājasa, als zoon van Çiwa te boek staat.

De eerwaarde heer gaat aldus door:

Kșamātah manah sang kawìndrān ruměngö| ikang wwang rěngö sugyan akweha mithyā| ndan anggěgwane jana sang wṛddha tekā | pilih nyūna sugyādhikā tã̃ calāna \| 3 \|

D. i. "De dichtervorst zij bij 't aanhooren toch vergevingsgezind. Van wat men hoort ${ }^{1}$ is er mogelijk veel dat valsch is; edoch, men stelle vertrouwen in lieden die vroed zijn, in dat geval. Misschien ontbreekt er iets; mogelijk is er iets te veel; dat worde niet kwalijk genomen.» "

In Zang XL tot XLXI volgt dan 't geschiedverhaal, te beginnen met de regeering van Rājasa tot aan de troonsbestijging van Hayam Wuruk. Het geheel is vertaald in deze Bijdragen D. 61, 403 en D. 63, 1, vgg. Wij gaan dus over tot Zang L, waar het jachtvermaak van den jongen Koning beschreven wordt.

\section{ZANG L.}

De verzen zijn in Praharsaṇì-maat.

Warṇṇan Çrì-ṇ̣pati mahas mareng paburwan | mańkat sāyudha saha bhṛtya len rathāçwa| ngkāneng Nandanawana ${ }^{2}$ kānanātidurgga | kaywanyādbhutatara kāça muñja kìrṇṇa \|i 1 ||

1 De constructie van w wang rĕngö is mij niet recht duidelijk. Wellicht is het een samengestelde uitdrukking voor "overlevering."

2 De tekst heeft $\mathrm{nandaka}$, stellig een schrijffout. 
D. i. "Er zal beschreven worden hoe de Vorst er op uitging naar zijn jachtgebied ${ }^{1}$. Hij maakt zich op met wapens, met dienaren en wagens en paarden, naar 't Nandanawana, een zeer moeielijk begaanbaar woud, met zeer verbazend (zwaar) geboomte en overal begroeid met kāça- en mu ñja-gras» ${ }^{2}$.

Nandanawana is de bekende naam van Indra's hemelschen lusthof, doch hier blijkbaar toegepast op een koninklijk jachtgebied.

Medran tang bala balabar huwus maněngkö | lāwan syandana madan angrapět rangköt | kedran tang wana wanaranya kagyat awri | awrĕg pakși nika mapakṣa mūra kegu $\|2\|$

D. i. "De troepen maakten een omtrekkende beweging: van alle kanten sloten zij 't veld af ${ }^{3}$, en de wagens stonden gereed dicht aanééngesloten ${ }^{4}$. Het bosch werd omringd, de apen waren onthutst en bevreesd; de vogels, in beroering, besloten, ontsteld, weg te vliegen.»

Deze strofe vertoont als stijlsieraad eenige voorbeelden van klankspeling, nl. bala bala ${ }^{\circ}$ in den eersten regel; dana dana en $\mathrm{ra}^{\circ} \mathrm{ra}^{\circ}$ in den tweeden; wana wan $a^{\circ}$ in den derden en $\mathrm{pak}^{\circ} \mathrm{pak}^{\circ}$ in den vierden. De geheele Zang draagt blijk dat de dichter zich beijverd heeft om met zijne schildering van de jacht een litterarisch kunstwerk te leveren.

Hūng ning bhṛtya mawurahan matunwatunwan | ghūrṇṇāwarṇṇa pasurak ing tasik guměntěr | untab ny agni nikā dudug ring antarāla | sākṣat Kāṇ̣awawana de hyang Agnï ngūni || 3 ||

D. i. "Het geschreeuw der dienaren weêrgalmde, terwijl zij

1 Een meer letterlijke vertaling volgens 't idioom onzer taal ware: „ging in 't jaaggebied zwerven".

${ }^{2} \mathrm{Ka}$ ça is Saccharum spontaneum, dus Jav. glagah; muñja rietgras.

8 Manĕngkö, waarvan 't hedendaagsch Jav. an ĕngkĕr een bijvorm is, heeft tot stam sĕngkö, niet sĕngkĕ, zooals KBWd. heeft; ook de aldaar opgegeven beteekenissen zijn verkeerd. Natuurlijk is sĕngkö, niet sĕngkĕ de ware spelling; men vergelijke o. a. rĕngö met Mal. dĕngar, Bis. dongog, Tag. dingig, enz. De juiste spelling komt ook in proza voor, o. a. in Wirāțaparwa, blz. 35 , in ka s ěng kö.

4 Rangköt komt overeen met Jav. rĕngkět; bijvormen zijn rĕngkĕd, rungkud. Het woord ontbreekt in KBWdb. 
den brand er in staken; daverend als het donderend geloei des oceaans. Het opvlammende vuur bereikte de tusschenruimte, evenals (toen) 't Khāṇḍawa-woud voorheen door den god Agni (verbrand werd)."

Tonton tang mṛga malay ū ndatan wri rātnya| kewran wibhrama marebut haręp marampak | apan minggat abalabar kkarěs nikenggì | hetunyākukud umusì těngah matimbun $\|4\|$

D. i. "Men zag de herten (of: wilde dieren) vluchten, niet wetende waar zich te bergen. Radeloos liepen zij her en derwaarts, zich beijverende om de voorsten te zijn in dichte drommen. Daar zij in hun bange vrees van alle kanten zich uit de voeten maakten, weken zij naar 't midden, bij hoopen.»

Kwehnya lwir ggawaya ri gobrajāprameya|

lwir goh ring wṛ̦abḥapurāngeběk prakìnṇna|

wök sěnggah gawaya lulāya çalya cihna |

godheya plawaga wị̣āla gaṇ̣akādî \| 5 \|

D. i. "Hun menigte was als van tallooze Gawaya's ' in Gowraja ${ }^{2}$; van runderen in Wrṣabhapura ${ }^{3}$ tot stoppens vol. (Er waren) evers, reeën, Gawaya's, buffels, stekelvarkens, hazen ${ }^{4}$, leguanen, apen, katten, neushoorns enzoovoorts.»

Satwāsing sahana rikeng alas pralabdha| kapwātūt manah ika tan hana wirodha| kadyāhěm pinaka jurunya tang mṛgendra| ngkāne sạ̣dịng ika çiwā marěk tan enggì $\|6\|$

D. i. "De dieren, zooveel als er in 't woud waren, waren in de klem. $Z_{\mathrm{ij}}$ waren allen eensgezind; geen was er die een tegenstrijdig gevoelen had. Als om raad te houden werd de leeuw als hun voorzitter gekozen; aan zijne zijde bevond zich de jakhals, onvervaard.»

1 Bos Gavaeus.

"Gowraja is is een "koekraal", doch hier schijnt een mythische plaats bedoeld.

s Dezelfde opmerking als in voorgaande noot. De eigenlijke beteekenis is "Stierenstad."

- Mijne vertaling van cihna berust op louter gissing; de hans, p̧ą̧a ৎą̧a, is namelijk het teeken van de Maan, çą̄àka. 
Ter opsmukking van zijne beschrijving van 't jachtvermaak des Konings, ontwerpt de dichter in zijne vruchtbare verbeelding een fantastisch beeld van de beraadslaging der in nood verkeerende wouddieren, die den inhoud vormt van den volgenden Zang.

\section{ZANG LI.}

De verzen zijn in de dichtmaat Pṛthwì. - De jakhals neemt het woord.

Kṣamākěna patakwan inghulun i sang mṛgendrādhipa| gati nrěpati $n$-angrarah gahana toh naya ndya ng gěgěn ${ }^{1}$ | angantya juga maty ring pangaděgan malaywā kuněng| mwang anglagana ${ }^{2}$ denya tulya hayuyun ${ }^{3} \operatorname{dinon}^{4} \tan$ murud $\|1\|$

D. i. "Het zij mij vergund een vraag te richten tot den vorst, heerscher over de wilde dieren ${ }^{5}$ : nu de Koning het woud afjaagt, welaan, zeg, welke gedragslijn er gevolgd moet worden.

Zullen wij maar afwachten om op de plaats waar wij staan te sneven? of zullen wij vluchten? of ook zullen wij tegenstand bieden, wanneer allen gelijkelijk daartoe gezind zijn, en. aangevallen wordende, niet terugdeinzen?

In to h ligt dikwijls de beteekenis van "welaan zeg!» Daar wat in 't KBWdb. er van opgegeven wordt, ten eenenmale onvoldoende is, mogen hier eenige aanhalingen volgen waaraan in de beteekenis duidelijk genoeg uitkomt. Zoo leest men in Sutasoma f. 94, b: toh ndy anung nitti; Smaradahana: toh ndy ang duhka sakeriya; Bhārata-Y. 33, 4: toh ndyānung naya ng enake kita; Bhoma-K.: toh, rakryan apati, ta paran tikāngulaha ni ngwang amawa bhuwana. Vaak kan men het vertalen eenvoudig met "welaan" of "komaan». Bijv. Bhoma-K. 110, 12: prabhu, toh haywa sandeha; Rāmāy. V, 7: ya ta walěsĕnta, toh kirakiran pějahanya huwus. Niet zelden ook past de vertaling: „eilieve!

\footnotetext{
1 Beter gĕgön.

2 Voor 't foutieve ala in den gedrukten tekst.

3 Deze vorm voor may uy u zeer verdacht.

4 Conjectuur voor dinoh.

5 D. i. de Leeuw.
} 
och toe»; zoo Arjuna-W. str. 149: ibu, toh, rumuhuna kita; eilieve! of «zeg eens!» str. 176: indung, toh syapa ta kitāri māsku.

Tulya is eigenlijk slechts een vertaling van paḍa, maar hier gebruikt op een wijze als in 't Skr. niet mogelijk is.

De rede van den jakhals vindt geen algemeene instemming, gelijk blijkt uit de nu volgende strofe.

Awarṇṇa kadi mangkanojar ikanang çrgālomarěk | ikang hariṇa kṛṣnasāra ruru cihna mojar wawang | yan i bwat i patikta tan hana muwah nayānung ${ }^{1}$ gěgěn | kalena saka ring malaya amalarolihäng ungsirěn $\| 2$ |

D. i. "Zóó ${ }^{2}$ sprak de jakhals ter audientie. De reebok, de zwartbonte antilope, het hert, de haas zeiden daarop: "Naar het gevoelen van (ons), Uwe nederige dienaren, is er geen andere gedragslijn te volgen dan te vluchten, in de hoop iets te vinden waar wij heen kunnen gaan.»

Met het gevoelen dezer vreesachtige dieren, konden andere zich niet vereenigen, zooals $\mathrm{zij}$ in de volgende strofe onverholen te kennen gaven.

Ikang gawaya serabha ${ }^{3}$ wrěṣabha len tarakṣāmuwus | aḍā wipatha kong kěnas tuhutuhun mṛāāpādhama| ndatar lěkasa ning sudhìra ng alayū mangantyā kuněng | si manglawana dharmma gěgwana malar tuměmwa ng hayu || 3 ||

D. i. "De Bos Gavaeus, de buffel, de stier en de hyena zeiden: "Schande! gij hebt het mis, reebok; gij zijt inderdaad een nietswaardig, gemeen wild dier. Het moet niet de handelwijze van den moedige zijn om op den loop te gaan of stilletjes af te wachten. Te kampen is een plicht die men vervullen moet, in de hoop van 't geluk te bejagen.»

$\mathrm{Nu}$ vat de leeuw 't woord op:

1 Conjectuur voor 't metrisch onmogelijke nayägĕgön.

${ }^{2}$ Awarṇna kadi mangkana is een omslachtige uitdrukking, schijnt het, voor anmangkana.

${ }^{3}$ Bedoeld is Skr. sairibha; de $a$ in de tweede lettergreep zal wel een afschrïversfout wezen. 
Mṛgendra sumahur ${ }^{1}$ kali paḍa wuwus ta yuktîkā gěgěn | nda yan wruha mabhedakěn sujana durjjanānung ${ }^{2}$ dělön| yan ing kujana wāhya solaha malaywa mangswa kuněng | apan wiwal angangga patyana těkapnya tanpadon $\|4\|$

D. i. "De leeuw antwoordde: "Uw beider rede is geschikt om daar gevolg aan te geven. Doch indien men verstandig is, makt men onderscheid tusschen de braven en de minder waardigen die men heeft gade te slaan. In 't geval van de minderwaardigen, is het openbaar hoe zij zich zullen gedragen ${ }^{3}$ of zij zullen vluchten of ten strijde rukken; immers zij zijn ongezind om te verdragen dat zij gedood worden, doordat het noodeloos is.

De leeuw gaat aldus voort:

Tuhun pwa yan i sang tripakșa rẹși Çaiwa Boddha tuwi| malaywa juga ng enakāngiringane sirān paṇdita|

kunang pwa kita yat kapanggihana těkap ${ }^{4}$ narendrāburu| angantya pati kewalāwwata huripta haywāgigu || 5 ||

D. i. "Wat nu echter de geestelijken van de drie secten: Rși's, Çiwaietische en Buddhịstische, aangaat, laat maar vluchten die lust heeft om hen te volgen, als zijnde geestelijke personen; of wel, indien gij door den Koning op jacht gevonden wordt, wacht dan slechts den dood af en biedt uw leven aan zonder weerzin.»

Tripakṣ a beteekent eigenlijk: "tot de drie secten behoorend». Onder 't substantivisch gebezigde woord, verstaat men, volgens een verklaring in KBWdb.: sang muni Çewabuddhaṛsi, d. i. "de Çiwaietische, Buddhistische asketen en Rṣi's», of wiku Çiwabuddharsi, d. i. "monniken, Çiwaietische, Buddhistische en Rși's». In ons gedicht Zang 81, 1 wordt ook gesproken van "de Tripakșa's in geheel Java», voor wier vaste positie de Koning groote zorg droeg. Vergelijkt men nu vs. 2 van denzelfden Zang, waar sprake is van wipra mwang Rși Çaiwa Boddha, Brahmanen en Rși's, Çaiwa's en Boddha's, dan komt men tot het besluit dat de Rṣi's een zeker

\footnotetext{
1 Gedrukt sumawur.

2 Conjectuur voor ${ }^{\circ} \mathrm{n}$ annung.

${ }^{3}$ Met andere woorden: het is niet twijfelachtig welk alternatief zij zullen kiezen.

${ }^{4}$ De tekst heeft tkan nare $e^{\circ}$.
} 
slag van asceten zijn en wel, heremieten en sannyāsins, anders genoemd bhikșu, monnik, welke de oud-brahmaansche leefregels volgden en ook in hun godsdienstig-wijsgeerige denkbeelden zich van Çiwaietische en Buddhistische geestelijken onderscheiden. Eigenlijk is de term Rṣi alleen toepasselijk op de Wijzen uit den voortijd.

Zeer eigenaardig is de wijze waarop de leeuw zijn uitspraak motiveert, zooals de nu volgende strofe te lezen geeft:

Apan ṇ̣pati yogya panghañutane ${ }^{1}$ hurip ning ${ }^{2}$ dadi

Bhațāra Giripaty amūrtti ri sirān wiçeșaprabhu|

awās hilanga pāpa ning pějaha de nirāmatyana|

lěwih saka ri kottamān ing alabuh ri sang hyang rạ̣u || 6 \|

D. i. "Want de Koning is bevoegd om aan 't leven der schepselen een einde te maken. God Giripati (Çiwa) is in hem als opperste heer belichaamd. Voor zeker zal de zonde van den stervende te niet gedaan worden wanneer men door Hem gedood wordt, eerder dan ten gevolge van de hooge daad van zich te storten in een heilig meer.»

Hier ziet men in den eersten regel zeer kras geformuleerd de stelling dat de Koning volstrekt meester is over leven en dood van zijne onderdanen, van alle schepselen. Dat recht ontleent de vorst aan de omstandigheid dat hij een god in menschengedaante is. Het is een niet onbekende theorie van absolutisme, zeer gepast in den mond van den hofdichter Prapañca, maar minder in dien vań den leeuw. Zeer eigenaardig is de voorstelling dat zonde wordt uitgewischt wanneer men door den heerscher gedood wordt, en voorts dat zelfmoord, als men zich in een heilig meer verdrinkt, als een uitstekende daad wordt beschouwd, waardoor men zich van zonde schoon wascht. Trouwens ook in Indië heerscht een soortgelijk geloof.

De leeuw zegt vervolgens:

Syapeka musuha kwa ri bhuwana yanpaḍe medhani| tathāpî ri sira tripakṣa mariris ngwang andoh wawang | pitowi haji yan ta katěmwa niyatāku kawwat hurip | ndatan muwaha satwajāti phala ning pějah de nira $\|7\|$

D. i. "Wie zou dan als vijand willen optreden, ter wereld,

1 Men verwacht mangha .

2 Zoo leze men voor wing. 
wanneer $\ldots{ }^{1}$. Nochtans, bij de geestelijken der drie secten mij aanstonds te verwijderen daarvan ben ik afkeerig ${ }^{2}$. Ik zal dan ook, indien ik met den Koning samentref, beslist mijn leven aanbieden; de vrucht van door Hem gedood te worden, zal wezen dat ik niet meer als dier zal geboren worden.»

1 De woorden paḍe medhani, of ọani versta ik niet. De lezing blijkt zeer verdacht.

${ }^{2}$ Die redeneering is mij niet recht duidelijk. 